\title{
AUSTRAL: 10 ANOS DE COOPERAÇÃO SUL-SUL
}

\section{Paulo Fagundes Visentini ${ }^{1}$ Guilherme Thudium²}

A política editorial que o Núcleo Brasileiro de Estratégia e Relações Internacionais (NERINT) priorizou, como centro pioneiro na área de Relações Internacionais (RI) no Sul do Brasil, foi a publicação de obras de referência destinadas aos novos cursos de graduação e pós-graduação que surgiam no país. Com a estruturação do Programa de Pós-Graduação em Estudos Estratégicos Internacionais (PPGEEI) na Universidade Federal do Rio Grande do Sul (UFRGS), surgiram as condições para que o NERINT estabelecesse uma parceria para a publicação de uma revista acadêmica. O nome AUSTRAL foi escolhido por significar Sul em português, espanhol, inglês, francês e alemão, além de outros idiomas, com mínimas variações ortográficas - e espelhava a opção pelo foco nas Relações Sul-Sul, com uma filosofia que privilegiou a cooperação com acadêmicos de todos os continentes, sem as competições corporativas suicidas, tão comuns nas universidades.

A independência, o rigor científico e a oportunidade para os estudiosos de países carentes do merecido espaço nas poderosas instituições do circuito Norte-Atlântico foram sempre prioridades. E criaram vínculos sólidos, revelando um outro mundo, pouco visível, mas possível, como era o lema do Fórum Social Mundial, antes de ser descaracterizado em "Fórum Temático" por militantes pós-modernos. Ao completar io anos, a AUSTRAL: Revista Brasileira de Estratégia e Relações Internacionais, discretamente, cumpriu o seu objetivo fundacional, congregando aqueles que são os verdadeiros agentes da transformação planetária em curso. Um espaço que reúne latino-

I Professor Titular de Relações Internacionais na Universidade Federal do Rio Grande do Sul (UFRGS). Coordenador do Núcleo Brasileiro de Estratégia e Relações Internacionais (NERINT) e Editor Fundador da AUSTRAL: Revista Brasileira de Estratégia e Relações Internacionais. Contato: paulovi@ufrgs.br.

2 Mestre em Ciência Política e Doutorando em Estudos Estratégicos Internacionais na UFRGS. Pesquisador do NERINT e Editor Assistente da AUSTRAL: Revista Brasileira de Estratégia e Relações Internacionais. Contato: guilherme.thudium@ufrgs.br. 
americanos, africanos e asiáticos, além de europeus e norte-americanos de visão verdadeiramente cosmopolita, em um projeto que busca contribuir para a superação da múltipla crise que a humanidade atravessa. Ciência e humanismo podem, e devem, caminhar juntos.

Mas que credenciais tinha o Brasil para lançar tal iniciativa, desde Porto Alegre, cidade localizada ao "Sul do Sul”? A política externa brasileira atingira, na primeira década do século XXI, uma projeção e um reconhecimento realmente mundiais, que aprimorou qualitativa e quantitativamente os grandes avanços da Política Externa Independente (I96I-64) e dos momentos marcantes do Regime Militar (I964-85), como o Pragmatismo Responsável e o Universalismo. Quantitativamente, a diplomacia brasileira se fez presente, além das regiões e parceiros tradicionais, nas pequenas nações africanas, asiáticas e do mundo árabe, nas ex-repúblicas soviéticas e até nos distantes arquipélagos do Oceano Pacífico, com papel decisivo desempenhado pelo Ministério das Relações Exteriores (Itamaraty) e por outros órgãos governamentais neste processo.

Do ponto de vista qualitativo, tal presença ganhou notável intensidade política, econômica e programática com a participação "ativa, afirmativa e propositiva" em importantes fóruns internacionais e organismos multilaterais, como o BRICS e o G-20, além da Organização Mundial do Comércio (OMC) e das Nações Unidas (ONU). Este avanço diplomático foi acompanhado pela expansão mundial e pelo crescimento da economia brasileira, que ultrapassou o PIB de vários países da Organização para Cooperação e Desenvolvimento Econômico (OCDE). O Brasil recebeu, igualmente, o status de Parceiro Estratégico da União Europeia e celebrou o mesmo vínculo com potências emergentes como a China e a Índia, assim como a África do Sul e outras importantes nações. A integração sul-americana avançou de forma consistente pela primeira vez, inclusive com iniciativas extrarregionais. Elevou-se, assim, o eixo da Cooperação Sul-Sul como prioritário para a diplomacia brasileira, com intensa presença na África e na Ásia.

Ainda que tais avanços tenham sido abordados no exterior e nas diversas revistas científicas nacionais, carecíamos de um veículo bilíngue (português ou espanhol e inglês) que estivesse focado exclusivamente na análise de tal desempenho. Ao mesmo tempo, faltava um instrumento que nos colocasse em contato direto com os demais centros de reflexão nos países em desenvolvimento, com os quais nos últimos anos estabelecemos contatos de alto nível - além dos acadêmicos e instituições que, no Norte, pensam criticamente as intensas transformações pelas quais está passando o moderno sistema mundial.

Assim, desde o estabelecimento do NERINT, em I999, a equipe de pesquisadores planejava a criação de uma revista científica que veiculasse 
suas pesquisas, pontos de vista e estabelecesse um diálogo com acadêmicos de outras nações, além dos membros do próprio corpo diplomático brasileiro. Para tanto, foram sendo feitos contatos no país e no exterior ao longo dos anos. Ela deveria refletir a perspectiva do mundo em desenvolvimento - o "Sul" -, e este sonho antigo se tornou realidade há exatos io anos, com o lançamento da AUSTRAL: Revista Brasileira de Estratégia e Relações Internacionais.

Foi o primeiro periódico do Brasil, na área de RI, a ser publicado integralmente em inglês. Em detrimento de tradutores profissionais, contudo, a revista procurou integrar alunos de graduação e pós-graduação da universidade na sua atividade editorial como forma também de capacitálos ao promover o contato direto com pesquisas científicas avançadas, sob a supervisão do seu corpo de editores e Conselho Editorial - como a professora Cristina Soreanu Pecequilo, a quem somos extremamente gratos pela diligente revisão dos esforços de tradução.

A revista contou com apoio inicial do Instituto de Pesquisa Econômica Aplicada (IPEA), think tank governamental vinculado ao Ministério da Economia do Brasil, e da Assessoria Internacional do Governo do Estado do Rio Grande do Sul. Atualmente, é financiada pelo Programa de Apoio à Edição de Periódicos Científicos (PAEP) da Pró-Reitoria de Pesquisa da UFRGS. Desta forma, a revista, desde sua concepção, esteve ligada tanto à intensa atividade de ensino de pós-graduação e pesquisa como à interlocução com órgãos oficiais e tomadores de decisão de todos os entes federativos - bem como aos grandes debates contemporâneos e científicos não só de RI, mas também de Estudos Estratégicos (Brodie I949).

\section{Uma Década de Diálogo com o Sul}

A AUSTRAL firmou-se, desde 20I2, como uma publicação essencialmente acadêmica voltada a temas políticos, securitários e econômicos internacionais, com ênfase na diplomacia dos países em desenvolvimento, que normalmente recebem atenção limitada ou etnocêntrica por parte das grandes revistas internacionais. Os focos da publicação, portanto, sempre foram as Relações Sul-Sul: as questões de segurança, o desenvolvimento econômico, político e diplomático das nações emergentes e suas relações com as potências tradicionais, diante de um contexto de crise e transição do sistema internacional, temática escolhida para o primeiro número da revista (v. I, n. I, 2OI2).

O tom foi, inicialmente, o de chamar atenção para uma crise global (geográfica e temática) em gestação. Logo, atentamos para a ocorrência de uma aceleração dos processos políticos, securitários e econômicos das RI. 
Finalmente, a partir de $20 \mathrm{I} 6^{3}$, podemos falar de um verdadeiro terremoto a sacudir a já frágil ordem mundial. Adentrou-se em uma verdadeira guerra de posições, que constitui o fio condutor que articula os conflitos e tensões contemporâneas. Muitos dos conflitos localizados e tensões regionais no Sul que são oriundos desse fenômeno, todavia, têm recebido uma atenção post factum da academia, de forma dissociada. Ainda carecíamos de uma reflexão totalizante que fosse capaz de interpretar, satisfatoriamente, os acontecimentos atuais de maneira integrada - uma lacuna que a AUSTRAL busca suprir desde a sua criação.

Ao priorizar também temas estratégicos e de segurança, a AUSTRAL logrou contribuir para o aprofundamento da reflexão sobre questões de enorme valor para a política externa, a defesa e o desenvolvimento do Brasil, conforme prenunciou o ex-Ministro da Defesa e das Relações Exteriores, Celso Amorim (20I2), em artigo de apresentação do primeiro número da revista. A edição inaugural contou também com um artigo do diplomata brasileiro Samuel Pinheiro Guimarães (20I2) sobre o futuro do Mercosul, além de dois artigos da casa sobre a política externa brasileira e a crise financeira de 2008 - cujos reflexos ainda eram sentidos globalmente - e contribuições internacionais sobre a política externa russa e sul-africana, o Fórum de Cooperação ChinaÁfrica e o papel dos países do Golfo Pérsico para a Cooperação Sul-Sul.

A AUSTRAL foi oficialmente lançada no Seminário Brasileiro de Estudos Estratégicos Internacionais (SEBREEI), evento realizado de 20 a 22 de junho de 2012 em Porto Alegre pelo Programa de Pós-Graduação em Estudos Estratégicos Internacionais (PPGEEI) da Faculdade de Ciências Econômicas da UFRGS, pelo Governo do Estado do Rio Grande do Sul e pelo Núcleo Brasileiro de Estratégia e Relações Internacionais (NERINT) sob a temática "Integração Regional e Cooperação Sul-Sul no Século XXI". A ampla aceitação obtida quando do seu lançamento foi consolidada e aprofundada com a edição de seu segundo número, que enfocou a Política Externa Brasileira e a Cooperação Sul-Sul, redigida principalmente por autores brasileiros e apresentada pelo Professor Amado Luiz Cervo (20I2), o Decano deste tema no Brasil.

Na última década do século $X X$, tendo sido encerrada a Guerra Fria, observou-se que os temas de segurança também passaram a ser negligenciados e eclipsados como objetos de estudo tanto na academia como no discurso político, no contexto da agenda predominantemente econômica da globalização neoliberal. Mas os atentados de II de setembro de $200 \mathrm{I}$

\footnotetext{
3 Curiosamente, 20 I6 é o ano que o influente acadêmico norte-americano John Mearsheimer (2019) identificou como marco transicional para um sistema internacional efetivamente multipolar.
} 
recolocaram a segurança no centro do debate acadêmico como parte da Guerra ao Terror e dos conflitos assimétricos e não-estatais. O enfoque adotado, no entanto, era direcionado à clivagem entre as potências Ocidentais e às novas ameaças dos grupos terroristas e dos chamados "Estados Párias".

Poucos foram os analistas que exploraram as dimensões geopolíticas implícitas em tal cenário. Ao se iniciar a segunda década do século XXI, o quadro sofreu substancial alteração: a crise econômica nos países da OCDE teve impacto no equilíbrio internacional, enquanto a China se tornava a segunda maior economia do mundo e o acrônimo BRICS ganhava substância e materialidade político-estratégica. Então, as análises sobre segurança ganharam nova dimensão, chegando ao Sul. E este foi o tema central do terceiro número da revista AUSTRAL, que inaugurou outro de seus objetivos fundantes, qual seja, a contribuição para a renovação teórico-analítica dos Estudos Estratégicos e internacionais.

Dentre as regiões austrais, a Revista também se destacou pela atenção dedicada à inserção estratégica da África nos assuntos internacionais - uma grave lacuna bibliográfica no Brasil, até o surgimento, a partir das pesquisas desenvolvidas no âmbito do NERINT, do Centro Brasileiro de Estudos Africanos (CEBRAFRICA) e da sua Revista Brasileira de Estudos Africanos (RBEA). O continente africano, num curto período de tempo, passou de uma situação de menor relevância para os analistas à de uma região de elevado valor estratégico. Todavia, a compreensão acadêmica dessa evolução foi dificultada, no Brasil, pelo desconhecimento da região.

À medida que o eixo do sistema mundial se desloca para o IndoPacífico, a África, por sua posição geopolítica e por seus novos vetores de inserção internacional, se torna um espaço extremamente relevante para o reposicionamento de forças em escala global. Trata-se de um espaço até então de baixa densidade estratégica, onde o emprego de recursos limitados pode ter um efeito ampliado. Mesmo os Estados Unidos, que até então pouco interesse haviam demonstrado em relação à África, se tornaram presentes e ativos, de forma acelerada. A Guerra ao Terror, o estabelecimento do AFRICOM (Comando dos Estados Unidos para a África) na Alemanha, a recriação das Frotas IV e V no Atlântico Sul e no Índico, respectivamente, e a crescente presença militar, econômica e política são alguns exemplos.

Tais processos ocorreram paralelamente ao lançamento da Nova Parceria para o Desenvolvimento Econômico da África (NEPAD) e da transformação da Organização da Unidade Africana (OUA) em União Africana (UA). Esses eventos contribuíram para avanços econômicos, sociais e políticos da África, que acarretaram mais autonomia e protagonismo diplomáticos das nações do continente, bem como maior inserção internacional dos acadêmicos e especialistas africanos. 
A AUSTRAL também teve papel decisivo na expansão e consolidação de teorias importantes de RI no Brasil, sejam elas clássicas ou críticas, como o estudo teórico, histórico e estratégico do sistema mundo, com foco na análise da alternância entre ciclos hegemônicos e de crises, e a noção de Sul Geopolítico, que contrapõe ao conceito amorfo de Sul Global. Mais do que criar um modismo teórico pós-moderno, a introdução do conceito de Sul Global representou uma estratégia de despolitizar o significado do terceiromundismo.

O Sul Global não se define por uma agenda positiva, mas negativa, pois, afinal, o Norte também não é "Global”? Assim, segundo o novo conceito não haveria sentido para a existência do Grupo dos 77 ou do Movimento dos Não Alinhados: todos os Estados do Sul se diluíram na globalização, e as principais nações desse espaço não passariam de "economias de mercado emergentes".

O Movimento dos Não Alinhados, contudo, seguiu existindo (e crescendo) e o aniversário de 60 anos da Conferência de Bandung, abordado na oitava edição da AUSTRAL, demonstraram a importância e a continuidade do terceiro-mundismo (v. 4, n. 8). Esses aspectos também foram explorados em importante artigo de autoria de Beatriz Bissio (20I6), uma das editoras dos famosos Cadernos do Terceiro Mundo. Como marca registrada da AUSTRAL, portanto, o Sul Geopolítico (Terceiro Mundo) se tornou não apenas o foco temático, mas também o eixo teórico e analítico da compreensão dos grandes problemas mundiais.

Neste sentido, publicamos também, em primeira mão, propostas analíticas inovadoras, como a dos "Eixos do Poder Mundial no Século XXI" (Visentini 20I9). Dentre as muitas formas de classificar as potências e as demais nações, buscou-se propor uma visão que desse conta das linhas de fratura que estão se formando, bem como das alianças que podem emergir de tal realidade. Nesse contexto, é paradoxal o discurso que emerge em diversos setores da sociedade e do Estado no Brasil (e em diversas nações). É como se a Guerra Fria houvesse renascido, contra toda a lógica, argumentos e fatos evidentes que sugerem o contrário, pois ela dependia de uma clivagem capitalismo versus socialismo - o qual sobrevive apenas de forma residual em pequenas nações. As rivalidades hoje, portanto, são de caráter predominantemente econômico e, em parte, geopolítico.

A proposta analítico-interpretativa em questão emergiu a partir das pesquisas e diálogo com a academia, a diplomacia, a mídia e as Forças Armadas, além de outros setores, e busca categorizar a política internacional hodierna em diferentes grupos. O primeiro deles se aglutina no eixo militarrentista anglo-saxão: Estados Unidos, Canadá, Reino Unido, Austrália, Nova Zelândia e, tangencialmente, Israel. O segundo é o eixo industrial desenvolvido 
da União Europeia, Japão e Tigres Asiáticos. O terceiro consiste no eixo industrial emergente, integrado pelas grandes nações do BRICS, especialmente a China e a Rússia, além da Turquia e Irã, onde a participação do Estado é determinante. Por fim, o quarto é o eixo agrário-mineral e humano periférico, integrado pelas nações médias e pequenas da América Latina, da África e da Âsia geográfica (que inclui o Oriente Médio). O Brasil e a África do Sul, absorvidos por suas agendas políticas internas, estão sob o risco de passar a integrar esse grupo. Acontecimentos recentes, como o tratado AUKUS entre Austrália, Reino Unido e Estados Unidos para a construção de submarinos nucleares para o país oceânico, sob fortes protestos de nações europeias como a França, parecem corroborar a proposta analítica em questão.

\section{Dossiês Temáticos}

Com a rápida consolidação do periódico e da sua crescente rede mundial de colaboradores e leitores, a Revista precisou expandir para conseguir absorver o fluxo de artigos. Assim, a partir da nona edição, a AUSTRAL ampliou seu rol de artigos por edição de dez para doze. Houve, igualmente, o aumento da demanda pela publicação de dossiês contendo resultados de pesquisas coletivas, que foram acolhidos conforme a qualidade e relevância temática. Um "problema" positivo, resultante de uma política editorial que não se atrelou aos cambiantes critérios das agências acadêmicas governamentais. O objetivo, que se mantém, sempre foi o de conectar autores e nações através da reflexão inovadora de uma área fortemente institucional como as RI.

A principal iniciativa neste sentido foi a publicação de um número especial (v. 7, n. I4) com um dossiê organizado pelos Professores Juliana Viggiano e Rafael Duarte Villa sobre "Segurança e Defesa na América do Sul”, nos marcos do Edital Pró-Defesa do Instituto Pandiá Calógeras do Ministério da Defesa e do Conselho Nacional de Desenvolvimento Científico e Tecnológico do Brasil (CNPq) - corroborando o desenvolvimento da temática de S\&D como uma tendência tanto da AUSTRAL, do NERINT e do PPGEEI.

Vale destacar, também, o "Dossiê Especial sobre as Relações BrasilAngola”, de autoria dos professores Fabio Morosini (UFRGS) e Michelle Ratton Sanchez Badin (FGV), publicado em 2016 e alusivo aos quarenta anos da independência do país africano; outro sobre o "Sistema Mundial: Teoria e Geopolítica", cujo conjunto de artigos abriu a última edição de 2020; e, mais recentemente ainda, um dossiê sobre América Latina que inaugurou a última edição da Revista com uma análise sobre os 30 anos de criação do Mercosul, de autoria do Professor Leonardo Granato (202I), demonstrando 
que cada década da (des)integração latina e sul-americana apresentou uma característica diferente, com períodos intercalados de expansionismo nãosustentado e de crise.

\section{Análises de Conjuntura}

A crescente contribuição de acadêmicos de um número cada vez maior de países evidencia a presença global e independente da AUSTRAL. E que o NERINT, após servir de elemento catalisador para a institucionalização dos estudos acadêmicos de RI no Sul do Brasil, segue, após duas décadas, analisando de forma séria, independente e criativa a situação internacional.

Além da semestral e bilíngue AUSTRAL, o NERINT também foi o berço da publicação bimestral Conjuntura Austral, editada pelo PPGEEI desde 20II. Inicialmente, a Conjuntura Austral ficaria encarregada das análises de cenário, em um enfoque mais imediato, ao passo que a AUSTRAL publicaria as análises academicamente mais densas. Todavia, com a evolução da projeção nacional e internacional do PPGEEI, ambas as revistas se tornaram referências análogas de alto nível na área, respeitadas as diferenças teóricas dos atuais corpos editoriais.

Por esse motivo, o NERINT também passou a oferecer um Boletim de Conjuntura (2016-20I9) digital e bilíngue, a cargo dos seus Pesquisadores Assistentes, Mestrandos e Doutorandos, com o intuito de retomar análises mais objetivas da conjuntura internacional para o público geral. Em 2020, a iniciativa do Boletim foi absorvida pela Análise Estratégica NERINT, que passou a integrar uma nova sessão regular da AUSTRAL, localizado na parte final de cada número. Ela traz breves notas de análise de conjuntura sobre acontecimentos internacionais atuais e relevantes, não contemplados nos artigos, redigidos por especialistas temáticos. Importantes acontecimentos internacionais tardam, normalmente, quase um ano para aparecerem como artigos acadêmicos tradicionais. Enquanto isto, a interpretação projetada sobre o público leigo e sobre a própria academia se resumem a artigos jornalísticos e às redes sociais. Portanto, urgia explicar de forma objetiva e urgente os grandes eventos internacionais, inicialmente no site do NERINT, transcrevendo-os semestralmente na Revista. 


\section{Indexadores e Estatísticas ${ }^{4}$}

A AUSTRAL está registrada em grandes indexadores e bases de dados mundiais: Scopus Elsevier, Google Acadêmico, LivRe!, Columbia International Affairs Online, Directory of Open Access Journals, ETHzürich, Journal TOCs, Latindex, Directory of Open Access Scholarly Resources, Sumários de Revistas Brasileiras, Beardsley Library Journals, WZB Berlin Social Science Research Center, GIGA Information Centre, Portal de Periódicos CAPES, Portal de Periódicos Científicos da UFRGS e Rede Cariniana.

A Revista já publicou autores de todos os continentes e regiões do mundo (em ordem cronológica de submissão): Brasil, Rússia, Canadá, África do Sul, Reino Unido, Países Baixos, Espanha, Austrália, Índia, Argentina, Turquia, Suécia, Alemanha, México, Paquistão, Zimbábue, Nigéria, Portugal, República Checa, Itália, Japão, Cabo Verde, Camarões, Cuba, China, Chile, Angola, Ucrânia, Cazaquistão, Estados Unidos, Costa Rica, Irã, Indonésia, Romênia, Equador, Colômbia, Paraguai, Polônia, Quirguistão, Malásia, Singapura e Nova Zelândia. Ao todo, são 257 autores, entre professores e doutores especializados nas temáticas privilegiadas pela Revista, oriundos de I43 diferentes instituições (ver Tabela I e Anexo).

Tabela 1 - Número de artigos e países por região (2012-2021)

\begin{tabular}{|c|c|c|c|}
\hline Região & Artigos & $\%$ & Países \\
\hline América do Sul & I65 & 64,2 & 6 \\
Europa & $3 \mathrm{I}$ & $\mathrm{I} 2, \mathrm{I}$ & $\mathrm{I} 3$ \\
Ásia & 28 & $\mathrm{IO}, 9$ & $\mathrm{IO}$ \\
África & 22 & 8,6 & 6 \\
América do Norte & 5 & $\mathrm{I}, 9$ & 3 \\
América Central & 3 & $\mathrm{I}, 2$ & 2 \\
Oceania & 3 & $\mathrm{I}, 2$ & 2 \\
\hline
\end{tabular}

Fonte: Elaboração de Felipe Werner Samuel com base no arquivo da AUSTRAL: seer.ufrgs.br/austral/issue/archive

A plataforma da Revista, que utiliza o Open Journal Systems (OJS) por meio do Portal de Periódicos da UFRGS, soma quase meio milhão de acessos às composições finais dos artigos (49I.392 acessos até outubro de 202I). A edição com o maior número de acessos foi publicada no segundo semestre de 20I3 sob o tema "Atlântico Sul, Brasil e a cooperação entre periferia e

4 Com a colaboração de Felipe Werner Samuel. 
semiperiferia". O artigo com maior número de visualizações, intitulado "Kwame Nkrumah e a visão pan-africana: entre a aceitação e a rejeição" foi publicado por Henry Kam Kah (2016), professor do Departamento de História da Universidade de Buea, Camarões. Já o artigo mais citado conforme o Google Acadêmico é o de autoria do professor australiano e brasilianista Sean W. Burges (20I2), publicado sob o título "Desenvolvendo a partir do Sul: Cooperação Sul-Sul no jogo de desenvolvimento global”.

Figura 1 - Citações da Austral na plataforma Google Acadêmico

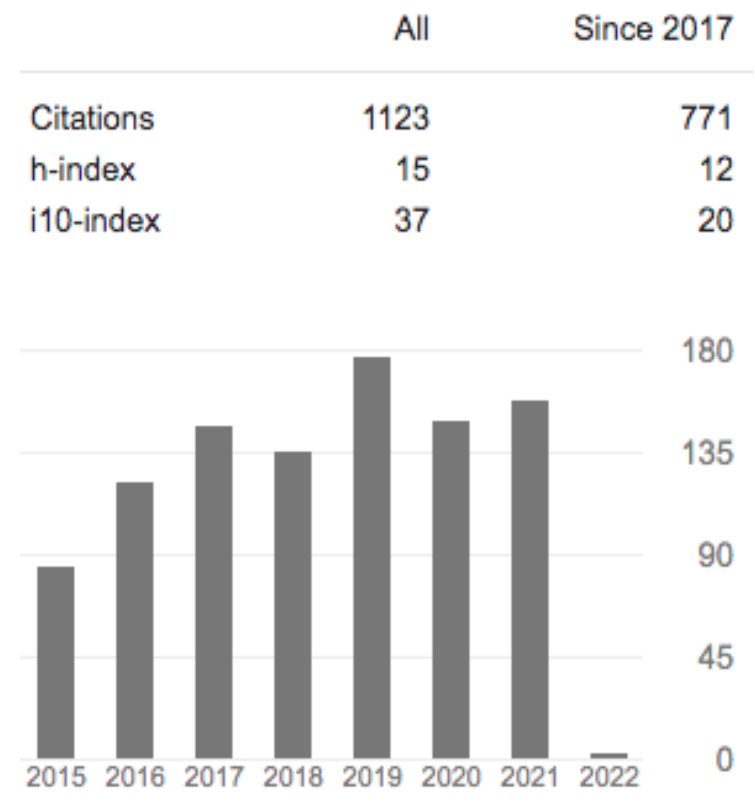

Fonte: Google Acadêmico (2022).

A dupla nomenclatura da Revista - AUSTRAL: Revista Brasileira de Estratégia e Relações Internacionais, em português, e AUSTRAL: Brazilian Journal of Strategy Q International Relations, em inglês -, bem como diferenças de grafia, prejudicou o periódico diante do novo sistema de avaliação, que parece ter reduzido a produção de conhecimento e redes colaborativas a meros algoritmos nas classificações em diversas listas e plataformas. Um erro técnico que a CAPES já corrigiu em 202I. Deste modo, a melhor maneira encontrada para indexar de forma integralizada tanto os artigos em inglês como em português da Revista foi por meio da criação de um perfil próprio na plataforma Google Acadêmico. Nele, obteve-se um alto número de citações 
(II23 ao todo e 898 entre 2016 e 202I), quando consideramos o formato bimestral da revista, que por sua vez é refletido nos índices $\mathrm{h}$ (valor I5) ${ }^{5}$ e h5 (valor I2) ${ }^{6}$ (ver Gráficos I e 2).

Gráfico 1 - Comparação dos índices h e h5 dos periódicos de estrato "A" da grande área de Ciência Política e Relações Internacionais*

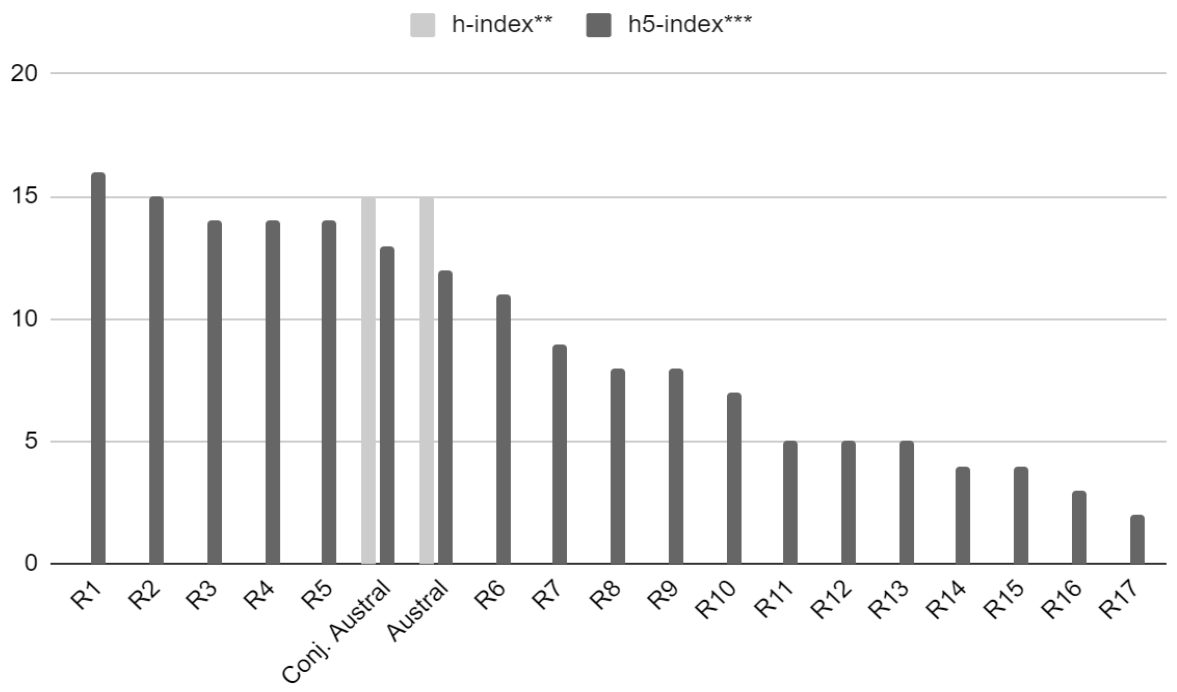

Fonte: Google Acadêmico, com base na Classificação de Periódicos da CAPES (Quadriênio 2013-2016 e Lista Provisória 2019). Dados referentes a outubro de 2021. Elaboração dos autores.

* Por cortesia acadêmica, os títulos dos periódicos externos à UFRGS foram suprimidos.

** 0 índice $\mathrm{h}$ da AUSTRAL e da Conjuntura Austral, ambas publicadas no âmbito da UFRGS, foram extraídos dos seus respectivos perfis no Google Acadêmico. *** 0 índice h5 foi extraído do perfil oficial dos periódicos no Google Acadêmico e, na ausência de um, por meio de busca no ranking da plataforma, tomando sempre o maior valor como referência: https://scholar.google.com.br/ citations?view_op=top_venues

$5 \mathrm{O}$ índice h é o maior número $\mathrm{h}$, sendo que h publicações possuem, no mínimo, h citações.

$6 \mathrm{O}$ índice h5 é o índice h dos artigos publicados nos últimos 5 anos completos. É o maior número $h$, de tal forma que $h$ artigos publicados em 2016-2020 têm, pelo menos, $h$ citações cada um. 
Destacamos, ainda, o alto número de artigos da AUSTRAL com, no mínimo, ıo citações cada (índice iıo) no Google Acadêmico (ver Gráfico 3):

Gráfico 2 - Comparação do índice i10 ltotal e últimos cinco anos completos) dos periódicos de estrato " $A$ " da grande área de Ciência Política e Relações Internacionais que possuem perfil próprio no Google Acadêmico*

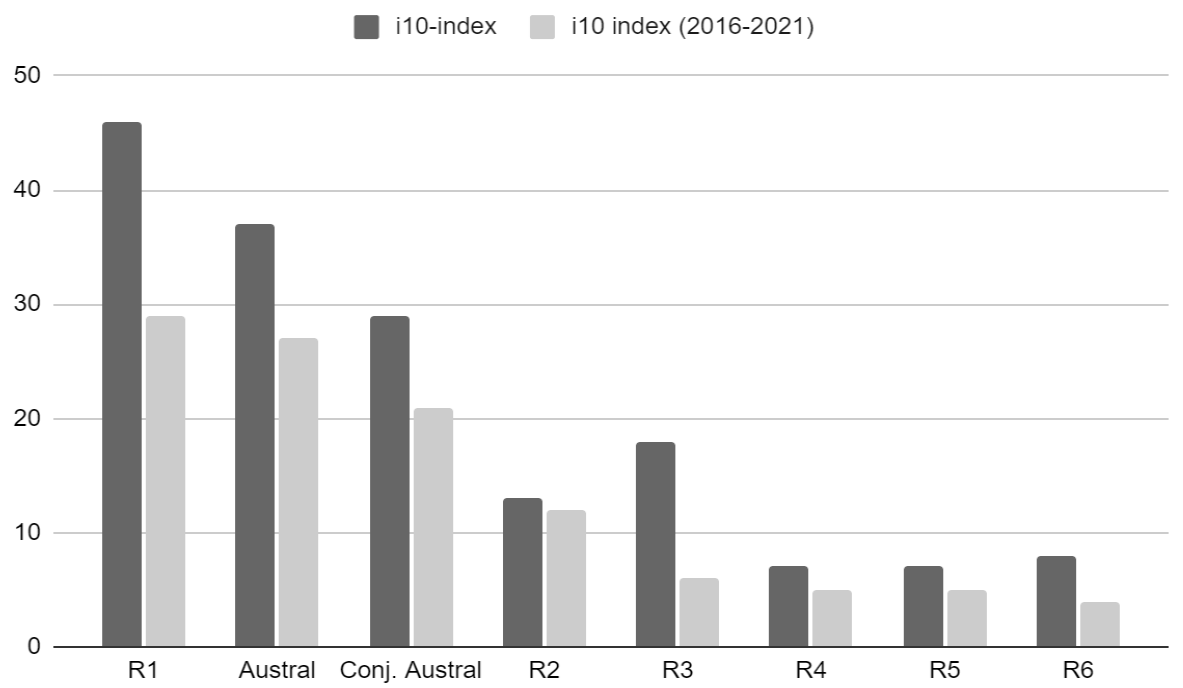

Fonte: Google Acadêmico, com base na Classificação de Periódicos da CAPES (Quadriênio 2013-2016 e Lista Provisória 2019). Dados referentes a outubro de 2021 . Elaboração dos autores.

* Por cortesia acadêmica, os títulos dos periódicos externos à UFRGS foram suprimidos. 


\section{REFERÊNCIAS}

Amorim, Celso. "Apresentação." AUSTRAL: Revista Brasileira de Estratégia e Relações Internacionais I, n. I (20I2): 7-8. https://seer.ufrgs.br/ austral/article/view/27983/17997.

Bissio, Beatriz. "Bandung, Não-Alinhados e mídia: o papel da revista 'Cadernos do Terceiro Mundo' no diálogo Sul-Sul.” AUSTRAL: Revista Brasileira de Estratégia e Relações Internacionais 4, n. 8 (20I6). https://doi. org/I0.22456/2238-6912.59957.

Brodie, Bernard. "Strategy as a Science.” World Politics I, n. 4 (I949): 467-88. https://doi.org/I0.2307/2008833.

Burges, Sean. "Desenvolvendo a partir do Sul: Cooperação Sul-Sul no jogo de desenvolvimento global." AUSTRAL: Revista Brasileira de Estratégia e Relações Internacionais I, n. 2 (20I2): 225-49. https:// doi.org/I0.22456/2238-6912.30I85.

Cervo, Amado Luiz. "A Política Exterior do Brasil." AUSTRAL: Revista Brasileira de Estratégia e Relações Internacionais I, no. 2 (2OI2): 9-I4. https://doi.org/10.22456/2238-6912.32620.

"Google Acadêmico." AUSTRAL: Revista Brasileira de Estratégia e Relações Internacionais. Google. Acesso em: I jan. 2022. https://scholar. google.com/citations?hl=pt-BR\&user=xuLxfQsynnEC.

"Google Acadêmico." Conjuntura Austral. Google. Acesso em: I jan. 2022. https://scholar.google.com/citations?hl=en\&user=4V7oKkMAAAAJ.

Granato, Leonardo. "Os trinta anos do Mercosul: apontamentos para um balanço" AUSTRAL: Revista Brasileira de Estratégia e Relações Internacionais Io, n. I9 (202I). https://doi.org/IO.22456/22386912.II2686.

Kam Kah, Henry. "Kwame Nkrumah e a visão pan-africana: entre a aceitação e a rejeição." AUSTRAL: Revista Brasileira de Estratégia e Relações Internacionais 5, n. 9 (2016). https://doi.org/10.22456/22386912.65783.

Pinheiro Guimarães, Samuel. "O futuro do Mercosul." AUSTRAL: Revista Brasileira de Estratégia e Relações Internacionais I, n. I (20I2): I3-22. https://doi.org/I0.22456/2238-6912.27989.

Mearsheimer, John J. "Bound to Fail: The Rise and Fall of the Liberal International Order." International Security 43, n. 4 (2019): 7-50. https://doi.org/ı.II62/isec_a_00342.

Visentini, Paulo Fagundes. "Eixos do poder mundial no século XXI: uma 
proposta analítica”. AUSTRAL: Revista Brasileira de Estratégia e Relações Internacionais 8, n. I5 (20I9): 9-24. https://doi. org/10.22456/2238-6912.91767.

\section{ANEXO}

Lista de instituições de origem dos autores publicados pela Austral: Revista Brasileira de Estratégia e Relações Internacionais nos últimos io anos. Elaboração: Felipe Werner Samuel, Pesquisador Assistente em nível de graduação do NERINT.

\begin{tabular}{|c|c|}
\hline Instituição creditada no artigo & País da Instituição \\
\hline ABCI Institute & Estados Unidos \\
\hline Academia Russa de Ciência & Rússia \\
\hline Ambrose Alli University & Nigéria \\
\hline Australian National University & Austrália \\
\hline Banco Central do Brasil/UFRGS & Brasil \\
\hline Cankiri Karatekin University & Turquia \\
\hline $\begin{array}{l}\text { Centro Austral de Investigaciones Científicas/ } \\
\text { CONICET }\end{array}$ & Argentina \\
\hline $\begin{array}{l}\text { Centro de Investigaciones de Política } \\
\text { Internacional }\end{array}$ & Cuba \\
\hline Christ University & Índia \\
\hline CIRAD & França \\
\hline Dalhousie University & Canadá \\
\hline ECEME & Brasil \\
\hline Ekiti State University & Nigéria \\
\hline Escola de Guerra Naval & Brasil \\
\hline $\begin{array}{l}\text { Escola Nacional de Ciência Política e } \\
\text { Administração Pública }\end{array}$ & Romênia \\
\hline Escola Superior de Economia & Rússia \\
\hline Escola Superior de Guerra & Brasil \\
\hline ESPM Sul / UNISINOS & Brasil \\
\hline Exército Nacional do Zimbábue & Zimbábue \\
\hline FACAMP & Brasil \\
\hline Facultad Latinoamericana de Ciencias Sociales & Equador \\
\hline FGV & Brasil \\
\hline
\end{tabular}




\begin{tabular}{|c|c|}
\hline FIRB & Brasil \\
\hline FUMEC & Brasil \\
\hline German Institute of Global and Area Studies & Alemanha \\
\hline $\begin{array}{l}\text { Hodja Ahmet Yassawi International Kazakh } \\
\text { Turkish University }\end{array}$ & Cazaquistão \\
\hline IFRS & Brasil \\
\hline Institute for Defense Studies and Analysis & Índia \\
\hline Institute of Strategic Research and Analysis & Paquistão \\
\hline $\begin{array}{l}\text { Instituto Brasileiro de Estudos de China Asia- } \\
\text { Pacifico }\end{array}$ & Brasil \\
\hline Instituto do Oriente & Portugal \\
\hline Instituto Rio Branco & Brasil \\
\hline $\begin{array}{l}\text { Instituto Superior de Relações Internacionais } \\
\text { Venâncio de Moura }\end{array}$ & Angola \\
\hline Isfahan University & Irã \\
\hline Islamic Azad University & Irã \\
\hline Istanbul Bilgi University & Turquia \\
\hline Itamaraty & Brasil \\
\hline John Cabot University & Itália \\
\hline Kazimierz Wielki University & Polônia \\
\hline King's College London & Reino Unido \\
\hline Landmark University & Nigéria \\
\hline $\begin{array}{l}\text { London School of Economics and Political } \\
\text { Science }\end{array}$ & Reino Unido \\
\hline \multicolumn{2}{|l|}{ Mercosul } \\
\hline Ministério da Defesa & Brasil \\
\hline National University of Singapore & Singapura \\
\hline PPG San Tiago Dantas & Brasil \\
\hline Programa de Estudios América Latina-África & Argentina \\
\hline PUCMG & Brasil \\
\hline Renmin University of China & China \\
\hline Ruprecht-Karls-Universität & Alemanha \\
\hline SDECT-RS & Brasil \\
\hline Momoyama Gakuin University & Japão \\
\hline Taras Shevchenko National University of Kiev & Ucrânia \\
\hline Tarbiat Modares University & Irã \\
\hline UEPB & Brasil \\
\hline UERJ & Brasil \\
\hline
\end{tabular}




\begin{tabular}{|c|c|}
\hline UFABC & Brasil \\
\hline UFBA & Brasil \\
\hline UFF & Brasil \\
\hline UFJF & Brasil \\
\hline UFMG & Brasil \\
\hline UFPB & Brasil \\
\hline UFPE & Brasil \\
\hline UFPEL & Brasil \\
\hline UFRGS & Brasil \\
\hline UFRJ & Brasil \\
\hline UFRRJ & Brasil \\
\hline UFS & Brasil \\
\hline UFSC & Brasil \\
\hline UFSCar & Brasil \\
\hline UFSM & Brasil \\
\hline UFU & Brasil \\
\hline UNB & Brasil \\
\hline UNESP & Brasil \\
\hline UniBH & Brasil \\
\hline UNICAMP & Brasil \\
\hline UNIFESP & Brasil \\
\hline UNILA & Brasil \\
\hline UniLaSalle-RJ & Brasil \\
\hline UNIPAMPA & Brasil \\
\hline UNISC & Brasil \\
\hline Unisinos & Brasil \\
\hline Universidad Autónoma de Madrid & Espanha \\
\hline Universidad Complutense de Madrid & Espanha \\
\hline Universidad de Buenos Aires & Argentina \\
\hline Universidad de Guadalajara & México \\
\hline Universidad de los Andes & Colômbia \\
\hline Universidad de Santiago & Chile \\
\hline Universidad Militar Nueva Granada & Colômbia \\
\hline Universidad Nacional da Costa Rica & Costa Rica \\
\hline Universidad Nacional de Rosario & Argentina \\
\hline Universidad Tecnológica de Mexico & México \\
\hline
\end{tabular}

24 Austral: Revista Brasileira de Estratégia e Relações Internacionais v.10, n.20, Jul./Dez. 2021 


\begin{tabular}{|c|c|}
\hline Universidade Afe Babalola & Nigéria \\
\hline Universidade Americana da Ásia Central & Quirguistão \\
\hline Universidade Anhembi Morumbi & Brasil \\
\hline Universidade Candido Mendes & Brasil \\
\hline Universidade Católica de Portugal & Portugal \\
\hline Universidade Católica de Temuco & Chile \\
\hline Universidade da África do Sul & África do Sul \\
\hline Universidade da Califórnia & Estados Unidos \\
\hline Universidade da Cidade de Macau & China \\
\hline Universidade da Indonésia & Indonésia \\
\hline Universidade da Nova Inglaterra & Austrália \\
\hline Universidade de Bucareste & Romênia \\
\hline Universidade de Cabo Verde & Cabo Verde \\
\hline Universidade de Gotemburgo & Suécia \\
\hline Universidade de Greenwich & Paquistão \\
\hline Universidade de Ibadan & Nigéria \\
\hline Universidade de Isfahan & Irã \\
\hline Universidade de Johanesburgo & África do Sul \\
\hline Universidade de Lagos & Nigéria \\
\hline Universidade de Leiden & Países Baixos \\
\hline Universidade de Montreal & Canadá \\
\hline Universidade de Salvador & Brasil \\
\hline Universidade de São José & China \\
\hline Universidade de Uppsala & Suécia \\
\hline Universidade de Waikato & Nova Zelândia \\
\hline Universidade Erasmus Rotterdam & Países Baixos \\
\hline Universidade Estadual da Paraíba & Brasil \\
\hline Universidade Estadual de Makassar & Indonésia \\
\hline Universidade Estatal de Moscou & Rússia \\
\hline Universidade Federal de Lafia & Nigéria \\
\hline Universidade Federal de Viçosa & Brasil \\
\hline Universidade Jawaharlal Nehru & Índia \\
\hline Universidade Lusíada Porto & Portugal \\
\hline Universidade Metropolitana de Praga & República Tcheca \\
\hline Universidade Nacional de Assunção & Paraguai \\
\hline Universidade Nacional de Defesa de Islamabade & Paquistão \\
\hline
\end{tabular}




\begin{tabular}{|l|l|}
\hline Universidade Nacional de Rosario & Argentina \\
\hline Universidade Nacional de San Martín & Argentina \\
\hline Universidade Privada de Angola & Angola \\
\hline Universidade Sun Yat-Sen & China \\
\hline Universidade Vinoba Bhave & Brasil \\
\hline Universitas Muhammadiyah Yogyakarta & Indonésia \\
\hline Universiti Sultan Zainal Abidin & Malásia \\
\hline University of Buea & Camarões \\
\hline University of Calabar & Nigéria \\
\hline University of Exeter & Reino Unido \\
\hline University of Johannesburg & África do Sul \\
\hline University of Zimbabwe & Zimbábue \\
\hline UNLa & Argentina \\
\hline USAL & Argentina \\
\hline USP & Brasil \\
\hline
\end{tabular}

